\title{
Simulasi Sistem Proteksi Petir Eksternal Dengan Metode Pembalik Muatan Menggunakan Matlab
}

\author{
Teguh Arfianto, Sabat Anwari, Rangga Okzadika Fitra Pratama \\ Jurusan Teknik Elektro, Fakultas Teknik Industri, ITENAS, Bandung \\ Email: teguh.arfianto@gmail.com
}

\begin{abstract}
ABSTRAK
Sistem proteksi petir merupakan suatu sistem yang sangat diperlukan pada saat ini, mengingat peralatan listrik semakin berkembang dengan pesat. Sistem ini melindungi kita serta peralatan listrik kita dari sambaran langsung. Di Indonesia sendiri sebagai kawasan dengan intensitas petir yang tinggi. Secara umum, sistem proteksi petir eksternal terdiri dari dua yaitu sistem proteksi Aktif dan sistem proteksi Pasif. Pada penelitian ini akan membahas tentang simulasi sistem proteksi petir dengan metode pembalik muatan dengan menggunakan prinsip kerja Op-Amp dalam MATLAB dimana dalam pengujiannya akan membandingkan dua buah finial dengan mengukur kuat medan listrik antara keduanya, dimana salah satu finial akan dipasang alat pembalik muatan, dan diberinya spark gap untuk proteksi peralatannya tersebut. Besar pengujian alat proteksi ini menggunakan tegangan impuls sampai $150 \mathrm{KV}$. Dalam pengujiannya hanya menggunakan parameter tegangan. Setelah diuji akan ada perbandingan dengan hasil perhitungan dan model sebelumnya.
\end{abstract}

Kata kunci: Sistem proteksi petir eksternal, muatan, op amp, spark gap, SIMULINK MATLAB.

\begin{abstract}
Lightning protection system is a system that is very necessary at this time, given the growing electrical appliances rapidly. This system protects us and our electrical appliances from direct strikes. In Indonesia itself as a region with high lightning intensity. In general, external lightning protection system consists of two namely Active protection system and Passive protection system. In this research will discuss about simulation of lightning protection system with reversing method by applying the working principle of OpAmp in MATLAB where in the test will compare two finials by measuring the electric field strength between the two, where one of the finials will be installed the reversing device, and he gave a spark gap for the protection of the equipment. Large testing of this protection tool using impulse voltage up to $150 \mathrm{KV}$. In the test just use the voltage parameters. Once tested there will be a comparison with the results of calculations and previous models.
\end{abstract}

Keywords: External lightning protection system, charge, op amp, spark gap, SIMULINK MATLAB. 


\section{PENDAHULUAN}

Indonesia memiliki tingkat hari guruh yang tinggi dengan jumlah sambaran petir yang banyak dan arus petir yang tinggi, sehingga kerusakan dan kerugian yang di timbulkan akibat sambaran petir pun cukup besar. Maka munculah berbagai teknologi untuk mengatasi sambarannya. Di dalam bidang teknik elektro dikenal dengan proteksi petir [1]. Dengan melihat proteksi petir yang ada saat ini, jika digabungkan dengan Sistem Inverting menggunakan Op-Amp, maka akan muncul Sistem Proteksi Petir Eksternal Dengan Metoda Pembalik Muatan, yang mana prinsip kerja dari alat ini berdasarkan pada Operasional Amplifer (Op-Amp) Inverting dan Sela Bola [2].

Dalam perancangan Sistem Proteksi Petir Eksternal Dengan Metoda Pembalik Muatan terbagi dalam beberapa proses, dari pembacaan muatan oleh Modul Referensi yang bekerja untuk membaca muatan yang berbanding terbalik dari muatan di awan, dikarenakan timbulnya elektromagnetik dari awan sebelum terjadinya sambaran langsung, sebagai input referensi Op-Amp. Prinsip kerja Op-Amp Inverting itu sendiri akan membalikan fasa masukan yang diambil dari Modul Referensi. Dan Sela Bola disini digunakan untuk melindungi perlatan Inverting bila terjadi sambaran langsung, pada saat terjadi sambaran maka fungsi dari sela bola ini akan menyalurkan arus petir ke Bumi. Untuk daerah yang dilindungi menggunakan metode Bola Gelinding dan Mesh sebagai sistem groundingnya.

\subsection{Metodologi Penelitian}

\section{METODOLOGI}

Pada bab ini akan dibahas metode pelaksanaan dari perancangan Sistem Proteksi Petir Eksternal Dengan Metoda Pembalik Muatan. Selanjutnya sistem dirancang sesuai dengan parameter yang diinginkan. Perangkat lunak MATLAB digunakan untuk memperoleh Tegangan Impulse dan proses pembalik fasa itu sendiri menggunakan Op-Amp. Pada perancangan dan simulasi ini hanya fokus membahas Tegangan input maupun output. Diagram alir proses perancangan dapat dilihat pada gambar 1.

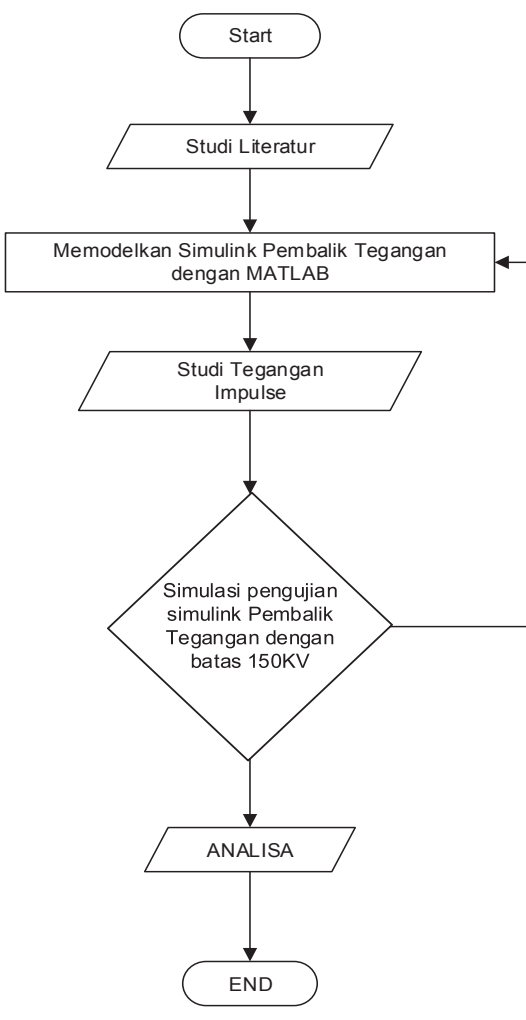

Gambar 1. Flow chart Metodologi desain Sistem Proteksi Petir Eksternal Dengan Metoda Pembalik Muatan 


\subsection{Op-Amp Inverting (Pembalik Muatan)}

Penguat operasional atau yang dikenal sebagai Op-Amp merupakan suatu rangkaian terintegrasi atau IC yang memiliki fungsi sebagai penguat sinyal, dengan beberapa konfigurasi. Secara ideal Op-Amp memiliki impedansi masukan dan penguatan yang tak berhingga serta impedansi keluaran sama dengan nol. Dalam prakteknya, Op-Amp memiliki impedansi masukan dan penguatan yang besar serta impedansi keluaran yang kecil. Op-amp memiliki simbol seperti yang terlihat pada gambar dibawah.

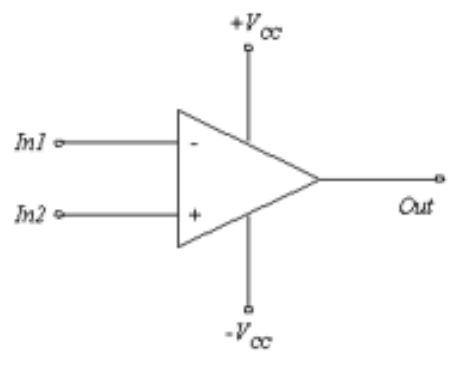

Gambar 2. Simbol Op-Amp

Secara garis besar, terdapat 4 pin utama dari Op-Amp, yaitu masukan inverting (tanda minus), masukan noninverting (tanda plus), masukan tegangan positif, masukan tegangan negatif dan pin keluaran. Di samping pin tersebut terdapat satu pin untuk adjustment.

\section{Penguat Inverting}

Penguat ini memiliki ciri khusus yaitu sinyal keluaran memiliki beda fasa sebesar $180^{\circ}$. Pada rangkaian penguat yang ideal memiliki syarat bahwa tegangan masukan sama dengan 0 dan impedansi masukan tak terhingga. Rangkaian untuk penguat inverting adalah seperti yang ditunjukkan gambar.

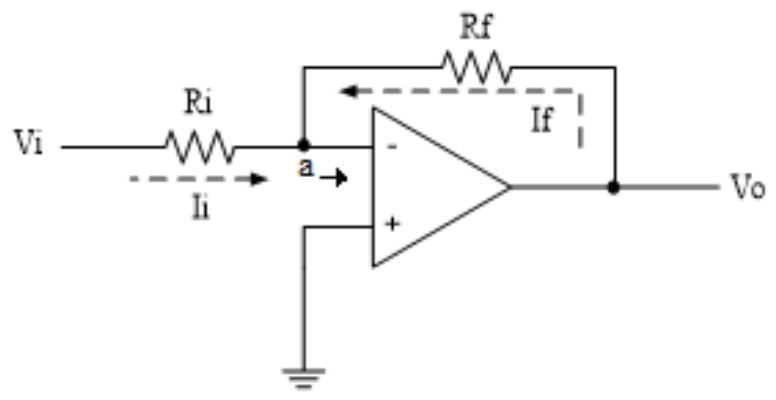

Gambar 3. Rangkaian Penguat Inverting

Sehingga dari rangkaian tersebut dapat diperoleh rumus penguat adalah sebagai berikut :

$i_{\text {in }}+i_{f}=i_{a}$

Dimana $\mathrm{i}=0$, maka

$i_{f}=-i_{\text {in }}$

$i_{f}=\frac{V_{\text {out }}-V_{a}}{R_{f}}=\frac{V_{\text {out }}-0}{R_{f}}=\frac{V_{\text {out }}}{R_{f}}$

$i_{\text {in }}=\frac{V_{\text {in }}-V_{a}}{R_{\text {in }}}=\frac{V_{\text {in }}-0}{R_{\text {in }}}=\frac{V_{\text {in }}}{R_{\text {in }}}$

Substitusi persamaan (9) dan (10) ke persamaan (8) sehingga diperoleh:

$\frac{V_{\text {out }}}{R_{f}}=\frac{-V_{\text {in }}}{R_{\text {in }}}$

$V_{\text {out }}=\frac{-R_{f}}{R_{\text {in }}} V_{\text {in }}$ 
Tanda (-) negatif menunjukkan terjadi pembalikan pada keluarannya atau memiliki beda fasa sebesar $180^{\circ}$ dengan masukannya.

Jika nilai $R_{1}=R_{2}$ maka besarnya tegangan output $V_{\text {out }}=-V_{\text {in }}[3],[4],[5]$.

\subsection{Model Pembalik Muatan Petir}

Gambar rancangan yang akan disumilasikan seperti bisa dilihat pada Gambar 4. Dengan pedoman dari sebelumnya pada Gambar 5. Dan simulasi yang akan digunakan adalah software MATLAB berbeda dengan studi sebelumnya yang menggunakan software Proteus. Lalu akan menganalisa sinyal Impuls sebagai referensi masukan, apakah fungsi kerja Op-Amp berjalan dengan baik.

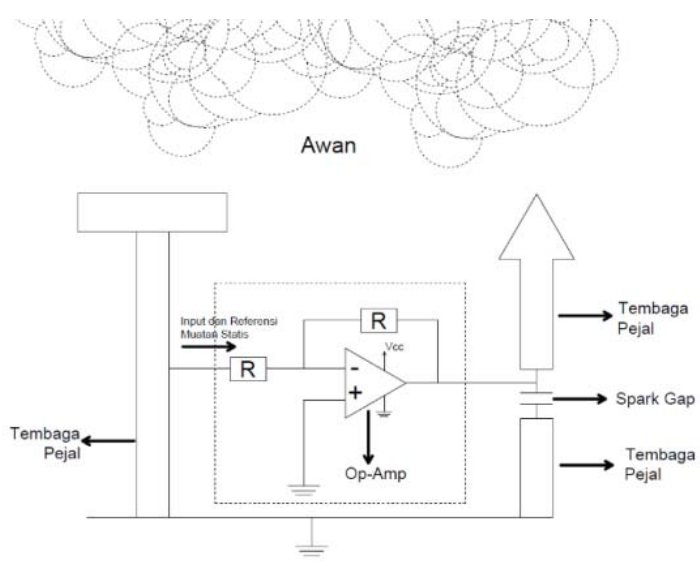

Gambar 4. Model Penangkal Petir inverting

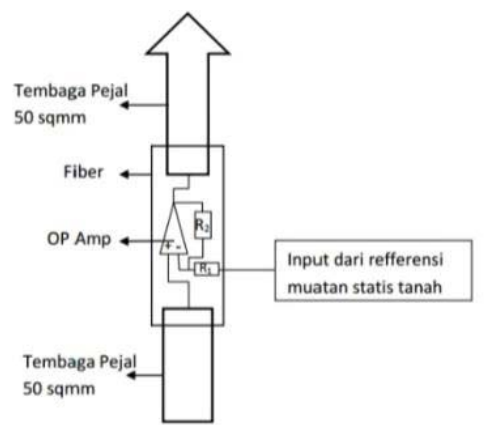

Gambar 5. Model Penangkal Petir konvensional

\subsection{Model Simulink Pembalik Muatan Petir}

Simulasi ini dibuat menggunakan program MATLAB yang dapat dijelaskan pada Gambar 6. Dimana Vimpulse disini sebagai input Tegangan Impulse yang dibaca oleh Modul Referensi. Model Sela Bola (Spark Gap) tidak dimasukan kedalam Simulasi karena itu hanya berbentuk mekanik.

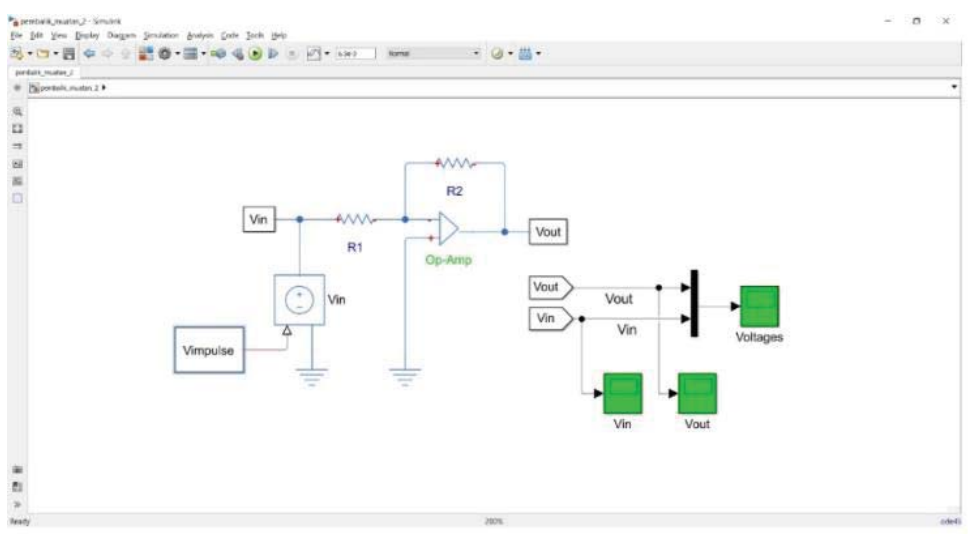

Gambar 6. Model simulink pembalik muatan petir 
Tabel 1. Ketentuan Tegangan Impulse pada Simulink MATLAB

\begin{tabular}{ccc}
\hline No & Percobaan & Tegangan \\
\hline 1 & 1 & $6,3 \mathrm{KV}$ \\
\hline 2 & 2 & $20 \mathrm{KV}$ \\
\hline 3 & 3 & $70 \mathrm{KV}$ \\
\hline 4 & 4 & $150 \mathrm{KV}$ \\
\hline
\end{tabular}

\subsection{Pengaplikasian Pembalik Muatan Petir}

Berikut desain mekanik yang ditunjukan pada Gambar 5.

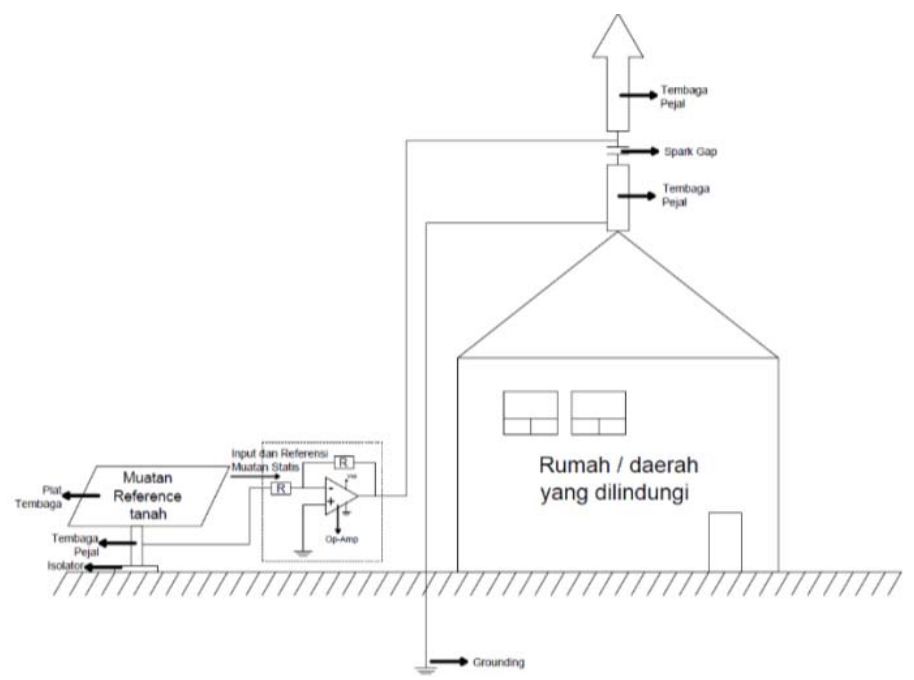

Gambar 7. Pengaplikasian pembalik muatan petir

\section{HASIL DAN PEMBAHASAN}

Pada bab ini berisi tentang hasil pengujian untuk seluruh percobaan yang dilkaukan di Simulink MATLAB serta pembahasan menegenai analisis dari pengujian yang dilakukan. Hasil pengujian yang didapat akan ditampilkan dalam bentuk gambar.

\subsection{Pengujian percobaan dengan Tegangan Input 6,3 KV}

Dari pengujian kondisi pertama ini didapat hasil pengujian yang ditunjukan pada Gambar 8 sebagai input dan Gambar 9 sebagai output. Dilihat dari hasilnya besar kedua tegangan sama besarnya tetapi berbeda fasa $180^{\circ}$ karena terjadinya proses inverting oleh rangkaian Op-Amp inverting. Dan sinyal output ini lah yang akan dikatakan sama dengan muatan yang ada di awan. Setelah muatan awan dan muatan proteksi petir sama maka tidak akan terjadinya beda muatan yang mengakibatkan terjadinya sambaran lansung petir.

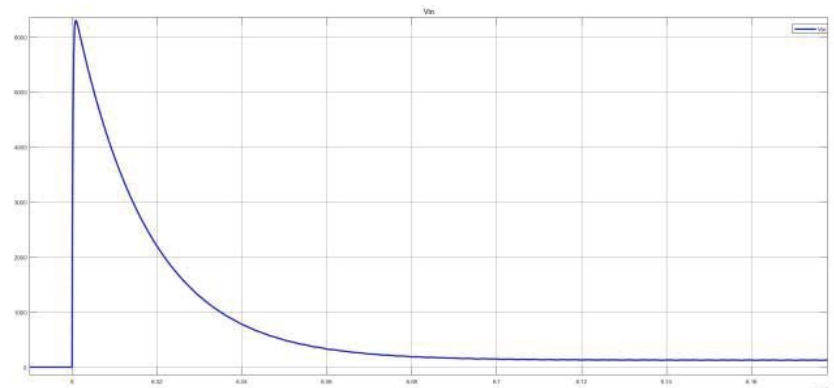

Gambar 8. Tegangan Input Op-Amp berupa Tegangan Impulse 6,3 KV 


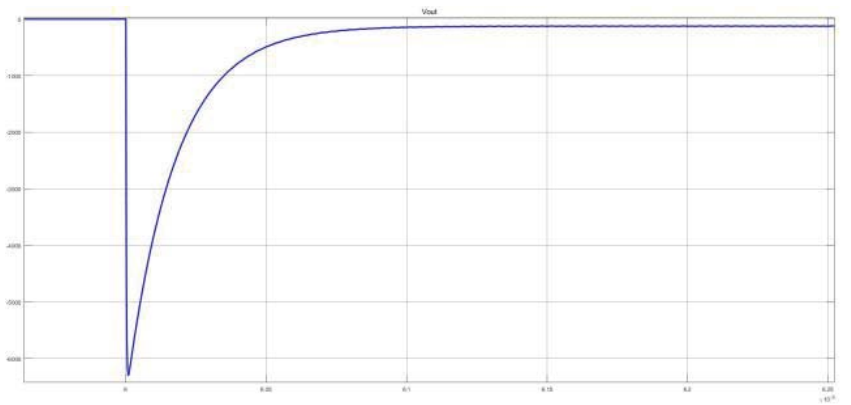

Gambar 9. Tegangan Output Op-Amp berupa Tegangan Impulse 6,3 KV

\subsection{Pengujian percobaan dengan Tegangan Input $20 \mathrm{KV}$}

Dari pengujian ini tidak ada perbedaan mencolok dengan percobaan pertama, tetapi hanya berbeda besar tegangan Input. Sistem kerjanya tetap masih sama dengan percobaan pertama, tetapi tegangan inputnya sebesar $20 \mathrm{KV}$.

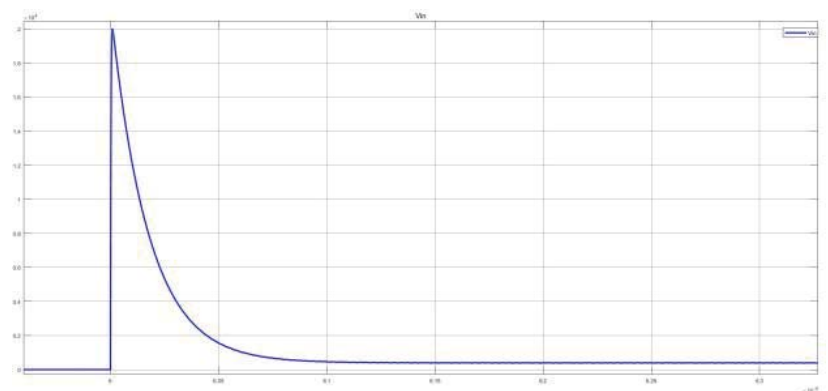

Gambar 10. Tegangan Input Op-Amp berupa Tegangan Impulse $20 \mathrm{KV}$

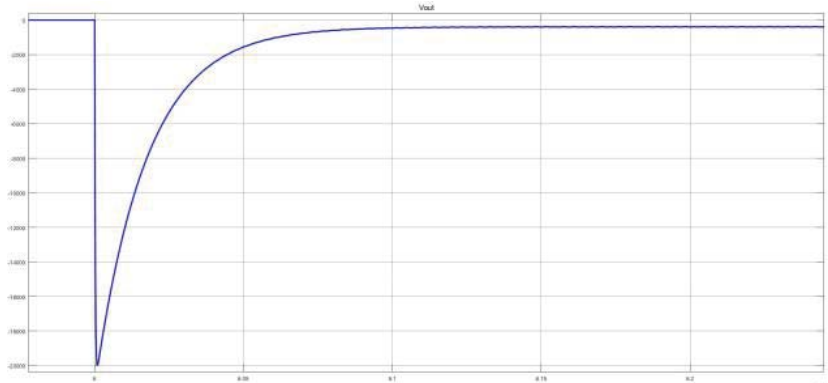

Gambar 11. Tegangan Output Op-Amp berupa Tegangan Impulse $20 \mathrm{KV}$

\subsection{Pengujian percobaan dengan Tegangan Input $70 \mathrm{KV}$}

Dari pengujian ini tidak ada perbedaan mencolok dengan percobaan pertama, tetapi hanya berbeda besar tegangan Input. Tetapi tegangan inputnya sebesar $70 \mathrm{KV}$.

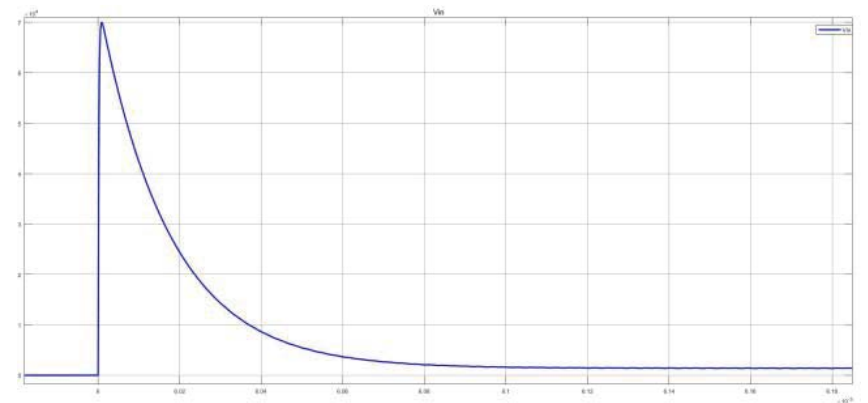

Gambar 12. Tegangan Input Op-Amp berupa Tegangan Impulse $70 \mathrm{KV}$ 


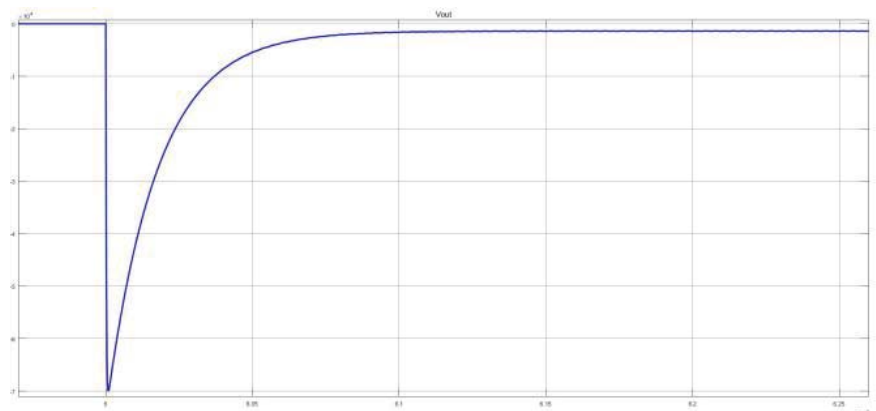

Gambar 13. Tegangan Output Op-Amp berupa Tegangan Impulse $70 \mathrm{KV}$

\subsection{Pengujian percobaan dengan Tegangan Input $150 \mathrm{KV}$}

Dari pengujian ini tidak ada perbedaan mencolok dengan percobaan pertama, tetapi hanya berbeda besar tegangan Input. Tetapi tegangan inputnya sebesar $150 \mathrm{KV}$.

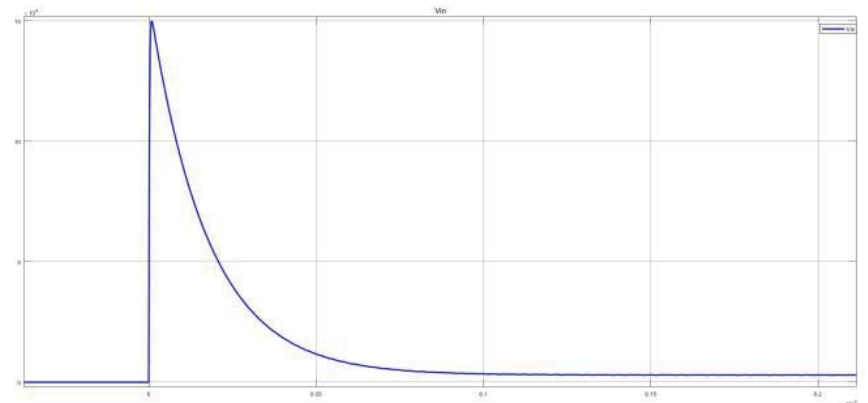

Gambar 14. Tegangan Input Op-Amp berupa Tegangan Impulse $150 \mathrm{KV}$

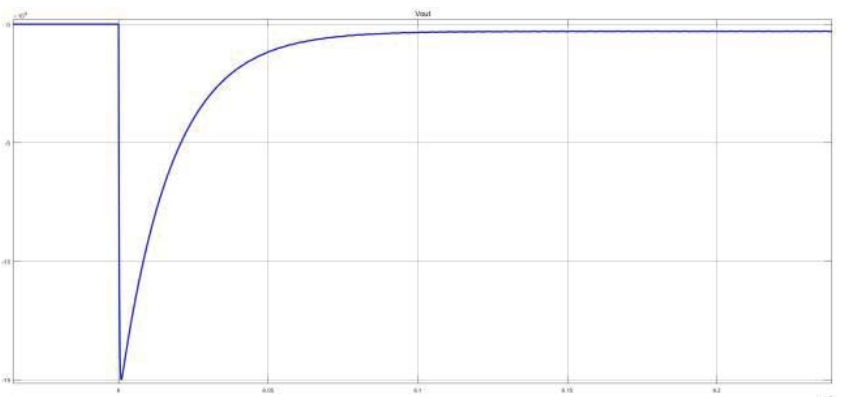

Gambar 8. Tegangan Output Op-Amp berupa Tegangan Impulse $150 \mathrm{KV}$

\section{KESIMPULAN}

Dari hasil penelitian ini bisa ditarik kesimpulan sementara bahwa rancang bangun Sistem Proteksi Petir Eksternal Dengan Metoda Pembalik Muatan bisa digunakan atau diimplementasikan sebagai teknologi terbaru untuk Sistem Proteksi Petir Eksternal. Dilihat dari data yang didapat dari hasil percobaan menggunakan MATLAB.

Dalam perancangan Sistem Proteksi Petir Eksternal Dengan Metoda Pembalik Muatan terbagi dalam beberapa proses, dari pembacaan muatan oleh Modul Referensi yang bekerja untuk membaca muatan yang berbanding terbalik dari muatan di awan, dikarenakan timbulnya elektromagnetik dari awan sebelum terjadinya sambaran langsung, sebagai input referensi Op-Amp. Prinsip kerja Op-Amp Inverting itu sendiri akan membalikan fasa masukan yang diambil dari Modul Referensi. Dan Sela Bola disini digunakan untuk melindungi perlatan Inverting bila terjadi sambaran langsung, pada saat terjadi sambaran maka fungsi dari sela bola ini akan menyalurkan arus petir ke Bumi. Untuk daerah yang dilindungi menggunakan metode Bola Gelinding dan Mesh sebagai sistem groundingnya. 
Dari pengujian kondisi pertama ini didapat hasil pengujian yang ditunjukan pada Gambar input dan Gambar output. Dilihat dari hasilnya besar kedua tegangan sama besarnya tetapi berbeda fasa $180^{\circ}$ karena terjadinya proses inverting oleh rangkaian Op-Amp inverting. Dan sinyal output ini lah yang akan dikatakan sama dengan muatan yang ada di awan. Setelah muatan awan dan muatan proteksi petir sama maka tidak akan terjadinya beda muatan yang mengakibatkan terjadinya sambaran lansung petir.

\section{DAFTAR PUSTAKA}

[1] Yen-Hong A. Chen, dkk (2017). "Assessment to Effectiveness of The New Early Streamer Emission Lightning Protection System”, International Journal On Smart Sensing And Intelligent Systems, Southern Taiwan University of Science and Technology.

[2] Siti Saodah, dkk, (2014)."Studi Awal Alat Proteksi Petir Dengan Metode Pembalik Muatan", Jurnal Seminar Nasional ke-9: Rekayasa Teknologi Industri dan Informasi, STTNAS, Yogyakarta.

[3] Elektrowiki. 2016. Op-Amp Inverting dan Non Inverting. Dipetik pada 18 November 2017 dari https://elektrowiki.wordpress.com/2016/10/16/op-amp-inverting-dan-non-inverting/.

[4] Robert L. Boylestad, and Louis Nashelsk. (2016), Electronic Devices and Circuit Theory Eleventh Edition.

[5] T S Rathore, (2011). “A Single Op Amp Digitally Programmable Circuit for Minimal Realization of Arbitrary Gains", International Journal of Engineering and Technology, St Francis Institute of Technology, Mumbai 400 103, India. 